\title{
Mitral regurgitation in coronary heart disease
}

\author{
KLAUS GAHL, ${ }^{1}$ RICHARD SUTTON, MICHAEL PEARSON, ${ }^{2}$ \\ PETER CASPARI, ${ }^{3}$ ANDRES LAIRET, ${ }^{4}$ AND LAWSON MCDONALD
}

From the National Heart Hospital and Institute of Cardiology, London

Mitral regurgitation is a relatively common finding in coronary heart disease. In this series of 127 patients, selected with a view to coronary or left ventricular surgery on the basis of severity of symptoms, the incidence was 39 (31\%). Mitral regurgitation is significantly more common in patients with a history or electrocardiographic evidence of previous myocardial infarction. Clinically it may present as a pan-or late systolic or even a mid-systolic, ejection type murmur at the apex or at the left sternal edge; but in 39 per cent of the patients with angiographic mitral regurgitation no murmur was present. Angiographically important mitral regurgitation (grades 2-4/4) was usually associated with a systolic murmur; this finding was independent of ejection fractions. Left ventricular enlargement clinically or radiographically is likely to accompany mitral regurgitation but left atrial enlargement (electrocardiographically or on chest $x$-ray) is a more reliable pointer to mitral regurgitation and pulmonary venous hypertension is even more strongly suggestive of its presence. The electrocardiographic signs of papillary muscle infarction were rare in this series (15\%) and were not related to angiographic mitral regurgitation. There was no difference in the incidence of mitral regurgitation in association with anterior or inferior myocardial infarction or in distribution of coronary artery disease. There is, however, a higher incidence of mitral regurgitation in more severe coronary arterial disease $(P<0.05)$. The incidence of mitral regurgitation is significantly higher with reduction in left ventricular ejection fraction $(P<0.001)$, with rise in the left ventricular end-diastolic pressure $(P<0.02)$, and with abnormal contraction patterns, but the severity of mitral regurgitation is not significantly related to these findings.

The integrity of the mitral valve is dependent upon the complex functional and spatial interrelationships of the valvar ring, its leaflets with their pinioning chordae tendineae, and the papillary muscles which are anchored in the ventricular wall (Puff et al., 1965; Silverman and Hurst, 1968; Burch et al., 1971; Heikkilä, 1971). This complex mechanism may be impaired by reversible myocardial ischaemia, or necrosis and fibrosis. Thus mitral regurgitation is not an uncommon transient or permanent finding in coronary heart disease (Phillips et al., 1963; Heikkilä, 1967, 1971; Burch et al., 1971; De Pasquale and Burch, 1971).

It is the purpose of this paper to assess the significance of clinical, electrocardiographic, haemodynamic, and radiological findings, from plain chest radiographs and ventricular and coronary

Received for publication 14 May 1976

${ }^{1}$ Clinical research fellowship granted by the German Academic Exchange Service; present address: Department of Internal Medicine, Hanover Medical School, Hanover, Germany.

'Present address: Brompton Hospital, London SW3.

3Present address: Royal North Shore Hospital, Sydney, Australia. 'Supported by a grant from the Vollmer Foundation, New York, U.S.A. angiocardiograms, with regard to the occurrence of mitral regurgitation in patients with proven coronary arterial disease. A preliminary report of this study was given to the British Cardiac Society (Gahl et al., 1972).

\section{Subjects and methods}

Investigations were made on 127 patients (111 men with mean age of $51 \pm 9 \cdot 1$ years and 16 women with mean age of $50 \cdot 1 \pm 15 \cdot 8$ years) with coronary heart disease being assessed with a view to aortocoronary venous bypass grafting or left ventricular surgery (Ross et al., 1972). All were severely symptomatic with angina pectoris resistant to medical treatment or incapacitating congestive cardiac failure. Patients were examined clinically, by electrocardiography, plain chest radiography, phono- and apex cardiography, and cardiac catheterisation with left ventricular and coronary angiocardiography. Betablocking drugs were discontinued at least 24 hours before the investigation; other drugs were continued. Non-invasive investigations were performed at a time closely related to cardiac catheterisation in 
70 unselected patients. Tracings were taken on a Cambridge Recorder at a paper speed of $100 \mathrm{~mm} / \mathrm{s}$ with two microphones, one at the apex and the other at the left sternal edge. The pulse pick-ups were placed at the site of maximum apical impulse and on the external carotid artery.

Routine right and left cardiac catheterisations were performed followed by selective coronary angiography (Petch et al., 1973). Mitral regurgitation was assessed from cineventriculograms in the right anterior oblique projection, and graded independently by two observers as slight, moderate, severe, and gross (grades 1 to 4). It was considered to be significant only if it occurred during normal systoles. In slight (grade 1) reflux there was only a faint puff of dye entering the left atrium; in moderate mitral regurgitation there was a distinct jet; in severe reflux there was a broad jet of dye passing across the mitral valve, and in grade 4 the entire left atrium was opacified immediately during the first systole with no distinct jet visible.

Left ventricular contraction on ventriculograms was graded as normal (1), local dyskinesis (2), aneurysm (3), or generalised dyskinesis (4). Local dyskinesis was defined as reduced but not absent inward systolic movement of part of the left ventricular wall compared with the adjacent wall. Aneurysm was defined as a localised enlargement of the ventricular cavity apparent in systole and usually in diastole, showing total lack of inward systolic movement, with or without paradoxical outward systolic movement. General dyskinesis was defined as poor overall contraction. The ejection fraction was measured using end-diastolic and endsystolic frames of one or more cardiac cycles. Cycles associated with arrhythmias were excluded. The films were not calibrated for magnitude which precluded measurement of absolute volumes. The localisation and the extent of coronary arterial disease were judged from cineangiograms and additionally in some cases from cut films. The coronary circulation was considered as a threevessel system with right, left anterior descending, and left circumflex vessels. A simple score system was used where normal arteries and less than 70 per cent stenosis was scored 1,70 to 99 per cent stenosis scored 2, and total occlusion scored 3. $\chi^{2}$ analysis was used for statistical comparisons.

\section{Results}

In the 127 patients, 39 had angiocardiographically demonstrable mitral regurgitation, which were subdivided into 13 patients with grade 1,13 with grade 2, 11 with grade 3 , and 2 with grade 4 regurgitation. Particular attention was paid to clinical signs suggestive of mitral regurgitation (systolic murmurs, a third heart sound, and palpable rapid filling waves).

Of the 39 patients with angiocardiographically demonstrable mitral regurgitation, $24(62 \%)$ had a systolic murmur which was apical in 22 and parasternal in 2. The apical murmur was pansystolic in 16 , mid-systolic in 3, and late-systolic in another 3 patients. The remaining 15 of the 39 patients with mitral regurgitation, however, had no systolic murmur. Angiocardiographically important mitral regurgitation (grades 2 to $4 / 4$ ) was usually associated with a systolic murmur and this finding was independent of left ventricular ejection fraction (Table 1).

In 29 patients, a murmur was heard without angiographic evidence of mitral regurgitation. In 13 patients this was apical, in 14 at the lower sternal

Table 1 Auscultatory, apex cardiographic, haemodynamic, and quantitative angiocardiographic data

\begin{tabular}{|c|c|c|c|c|c|}
\hline & $\begin{array}{l}88 \text { patients } \\
\text { without } M R\end{array}$ & $\begin{array}{l}39 \text { patients with } \\
M R\end{array}$ & $\begin{array}{l}13 \text { patients with } \\
\text { grade } 1 M R\end{array}$ & $\begin{array}{l}13 \text { patients with } \\
\text { grade } 2 M R\end{array}$ & $\begin{array}{l}13 \text { patients with } \\
\text { grade } 3 / 4 M R\end{array}$ \\
\hline Patients with systolic murmur & & 24 & 4 & 9 & 11 \\
\hline $\begin{array}{l}\mathrm{rfw} \\
\text { ' } \mathrm{a} \text { ' }\end{array}$ & $\begin{array}{r}6 \cdot 7 \pm 3 \cdot 7 \\
12 \cdot 0 \pm 12 \cdot 6\end{array}$ & $\begin{array}{l}12 \cdot 2 \pm 9 \cdot 4 \\
16 \cdot 2 \pm 8 \cdot 8\end{array}$ & $\begin{array}{l}15 \cdot 0 \pm 8 \cdot 5 \\
20 \cdot 0 \pm 9 \cdot 3\end{array}$ & $\begin{array}{l}13 \cdot 5 \pm 13 \cdot 1 \\
16 \cdot 3 \pm 6 \cdot 1\end{array}$ & $\begin{array}{r}6 \cdot 7 \pm 2 \cdot 9 \\
12 \cdot 3 \pm 10 \cdot 4\end{array}$ \\
\hline $\begin{array}{l}\text { LVEDP ' } a \text { ' } \\
\text { LVEDP post ' } a \text { ' } \\
\text { PC ' } v \text { ' } \\
\text { PC mean } \\
\text { PA mean }\end{array}$ & $\begin{array}{l}15 \cdot 4 \pm 7 \cdot 8 \\
14 \cdot 2 \pm 7 \cdot 6 \star \\
12 \cdot 7 \pm 6 \cdot 5 \\
10 \cdot 0 \pm 5 \cdot 7 \\
17 \cdot 5 \pm 7 \cdot 8\end{array}$ & $\begin{array}{l}20 \cdot 3 \pm 8 \cdot 0 \\
18 \cdot 3 \pm 7 \cdot 5^{\star} \\
21 \cdot 7 \pm 12 \cdot 3 \\
15 \cdot 1 \pm 8 \cdot 1 \\
25 \cdot 4 \pm 12 \cdot 1\end{array}$ & $\begin{array}{l}18 \cdot 8 \pm 5 \cdot 5 \\
16 \cdot 7 \pm 5 \cdot 6 \\
14 \cdot 8 \pm 8 \cdot 5 \\
11 \cdot 7 \pm 6 \cdot 4 \\
19 \cdot 0 \pm 9 \cdot 3\end{array}$ & $\begin{array}{l}23 \cdot 7 \pm 11 \cdot 1 \\
19 \cdot 7 \pm 9 \cdot 3 \\
24 \cdot 9 \pm 11 \cdot 8 \\
18 \cdot 8 \pm 8 \cdot 5 \\
31 \cdot 6 \pm 13 \cdot 7\end{array}$ & $\begin{array}{l}19 \cdot 2 \pm 7 \cdot 3 \\
18 \cdot 6 \pm 7 \cdot 2 \\
25 \cdot 9 \pm 13 \cdot 6 \\
15 \cdot 4 \pm 8 \cdot 4 \\
26 \cdot 1 \pm 10 \cdot 5\end{array}$ \\
\hline LV ejection fraction & $52 \cdot 9 \pm 19 \cdot 1 \star \star$ & $34 \cdot 6 \pm 20 \cdot 8 \star \star$ & $40 \cdot 1 \pm 21 \cdot 6$ & $27.5 \pm 20.5$ & $36 \cdot 7 \pm 20 \cdot 4$ \\
\hline
\end{tabular}

Abbreviations: $r \mathrm{fw}=$ rapid filling wave and ' $\mathrm{a}$ ' = ' $\mathrm{a}$ ' wave as percentage of systolic wave of apex cardiogram; $L V E D P=$ left ventricular end diastolic pressure; $P C=$ pulmonary wedge pressure; $P A=$ pulmonary arterial pressure. All pressures in mmHg.

For classification of MR (mitral regurgitation) see text.

The ranges given are in each case one standard deviation, and all variables are approximately normally distributed.

$\left.\begin{array}{rl}\star P & <0.02 \\ \star \star P & <0.001\end{array}\right\}$ unpaired Student's $t$ test. 
Table 2 Symptoms and signs of 127 patients with coronary heart disease according to presence or absence of angiocardiographically demonstrable mitral regurgitation

\begin{tabular}{|c|c|c|c|c|}
\hline & \multicolumn{2}{|c|}{$\begin{array}{l}\text { Patients } \\
\text { without } M R \\
\text { No. } \%\end{array}$} & \multicolumn{2}{|c|}{$\begin{array}{l}\text { Patients } \\
\text { with } M R \\
\text { No. } \%\end{array}$} \\
\hline Number of patients & 88 & & 39 & \\
\hline History of angina & 79 & 90 & 31 & 79 \\
\hline Previous myocardial infarct & 49 & 56 & 28 & 72^ \\
\hline Heart failure symptoms & 42 & 48 & 24 & 62 \\
\hline Palpable LV enlargement & 28 & 32 & 23 & 59 \\
\hline Third heart sound & 17 & 19 & 14 & 36 \\
\hline Fourth heart sound & 31 & 35 & 14 & 36 \\
\hline Electrocardiogram of LV hypertrophy & 15 & 17 & 9 & 23 \\
\hline Electrocardiogram of myocardial infarct & 55 & 62 & 32 & \\
\hline Electrocardiogram of LA enlargement & 21 & 24 & 20 & 51 \\
\hline Electrocardiogram of LV aneurysm & 19 & 22 & 12 & 31 \\
\hline
\end{tabular}

Abbreviations: $\mathrm{LV}=$ left ventricle; $\mathrm{LA}=$ left atrium; $\mathrm{MR}=$ mitral regurgitation.

$\star \mathrm{P}<0.05$

$\star \star P<0.001$ (using $\chi^{2}$ analysis).

edge, and in 2 cases at the pulmonary area.

The clinical and electrocardiographic findings were related to the presence or absence of angiographically demonstrable mitral regurgitation (Table 2). The duration of the history of angina pectoris did not differ in those with and without mitral regurgitation. History of previous myocardial infarction was significantly more common in patients with mitral regurgitation $(\mathbf{P}<0.05)$. Symptoms of heart failure were more frequent among patients with than without mitral regurgitation $(24 / 39=62 \%$ and $42 / 88=48 \%$, respectively) as was palpable left ventricular enlargement $(23 / 39=59 \%$ and $28 / 88=32 \%$, respectively) but these differences were not statistically significant. A third heart sound was audible in 17 of the 88 patients $(19 \%)$ without mitral regurgitation, and in 14 of the 39 patients $(36 \%)$ with mitral regurgitation, and a fourth heart sound was present in 31 patients $(35 \%)$ without mitral regurgitation and in $14(36 \%)$ with mitral regurgitation. Evidence of previous myocardial infarction, however, was the only feature among these which showed a statistically significant difference between the two groups.

Of the 39 patients with mitral regurgitation $32(82 \%)$ and of the 88 patients without mitral regurgitation, $55(62 \%)$ had electrocardiographic signs of infarction $(P<0.001)$. Infarction was anterior in 48 patients, 17 of whom (35\%) had mitral regurgitation, and inferior in 29 patients, 8 of whom ( $28 \%$ ) had mitral regurgitation. Of the 10 patients with anterior and inferior infarction, 7 had mitral regurgitation. Criteria of papillary muscle infarction (Phillips et al., 1963; Burch et al., 1971) were positive in 10 patients without mitral regurgitation $(11 \%)$ and in 9 patients with mitral regurgitation $(23 \%)$. Electrocardiographic evidence of left ventricular hypertrophy and left atrial enlargement (Morris et al., 1964) was slightly more frequent in the group with than in those without mitral regurgitation. Finally electrocardiographic signs of left ventricular aneurysm were found in 31 per cent of patients with mitral regurgitation and in 22 per cent of patients without mitral regurgitation. None of these differences except that of the electrocardiogram of the myocardial infarction was statistically significant.

The rapid filling wave and the 'a' wave of the diastolic phase of the apex cardiogram did not parallel the radiological grade of mitral reflux (Table 1). They were most obvious in grade 2 mitral regurgitation.

The ' $a$ ' wave and the post ' $a$ ' left ventricular enddiastolic pressures $(P<0.02)$ and related pressures in the pulmonary circulation (Table 1) clearly show a more severe disorder of left ventricular haemodynamics in patients with mitral regurgitation than in those without. There is, however, no significant difference between patients in each mitral reflux group and impairment of left ventricular ejection fraction. Grade 2 mitral regurgitation, however, is associated with most severely reduced ejection fraction. There was no correlation between the left ventricular systolic pressure and the incidence of mitral regurgitation.

Table 3 summarises the findings on plain chest radiographs and angiocardiography in patients with and without mitral regurgitation. As with the electrocardiogram, evidence of atrial enlargement and left ventricular hypertrophy was slightly more frequently encountered in patients with than in those without mitral regurgitation, though 29 patients with mitral reflux did not show left atrial enlargement. Pulmonary venous hypertension, however, was a stronger pointer to mitral regurgitation and correlated fairly well with the haemodynamic data. Left ventricular cineangiograms showed a higher incidence of abnormal contraction in patients with mitral regurgitation than in those

Table 3 Plain chest radiographic and angiographic findings according to angiocardiographic presence or absence of mitral regurgitation

\begin{tabular}{lcr}
\hline & $\begin{array}{c}\text { Patients } \\
\text { without }\end{array}$ & $\begin{array}{c}\text { Patients } \\
\text { with } \boldsymbol{M R}\end{array}$ \\
\hline Enlargement of LV & $17(19 \%)$ & $22(56 \%)$ \\
Enlargement of LA & $3(3 \%)$ & $10(26 \%)$ \\
Pulmonary venous hypertension & $13(15 \%)$ & $22(56 \%)$ \\
Normal LV contraction & $35(40 \%)$ & $7(18 \%)$ \\
Localised dyskinesis & $35(40 \%)$ & $12(31 \%)$ \\
LV aneurysm & $11(13 \%)$ & $10(26 \%)$ \\
Generalised poor contraction & $7(8 \%)$ & $10(26 \%)$ \\
\hline
\end{tabular}

None of the differences between the two groups reached statistical significance $(P<0.05)$ using $\chi^{2}$ analysis. 
without (see Table 1). Selective coronary angiography revealed a relative preponderance of right coronary arterial and left anterior descending coronary arterial disease compared with circumflex disease. The incidence of mitral regurgitation was evenly distributed in the various patterns of coronary disease. However, there was a tendency to more severe degrees of coronary arterial disease (using the simple score system described) in patients with mitral regurgitation than in those without $(\mathrm{P}<0.05)$.

\section{Discussion}

Mitral regurgitation is a relatively common finding in acute and chronic myocardial ischaemia (Friedberg, 1966; Heikkilä, 1971; Hurst and Logue, 1970; Segal and Likoff, 1964; Shelburne and Gorlin, 1972). It has been thought to be the result of (a) dysfunction of papillary muscles from acute ischaemia or irreversible fibrosis or necrosis (Burch et al., 1963; Phillips et al., 1963; Orlando et al., 1964; Heikkilä, 1967, 1971; De Pasquale and Burch, 1971); (b) rupture of papillary muscleleaflet connection (Cederqvist and Söderström,1964; Robinson, et al. 1965; Morrow et al., 1968); (c) ventricular wall dyskinesis (Burch et al., 1971 Shelburne and Gorlin, 1972), and aneurysm with abnormal spatial relations of the papillary muscles; (d) dilatation of the mitral valve ring in ventricular dilatation (Holloway et al., 1965; Friedberg, 1966); or (e) asynchronous contraction, e.g. in arrhythmias (Vandenberg et al., 1969), may lead to valvar regurgitation. The inconstancy of 'ischaemic mitral regurgitation' (Heikkilä, 1967, 1971; De Pasquale and Burch, 1971) necessarily renders statements of incidence imprecise. Figures varying from 8 per cent (Yater et al., 1948) to 55 per cent (Heikkilä, 1967) appear to depend upon the criteria used for selection. All patients included in this study have been investigated with a view to venous graft or left ventricular surgery; they all had severe symptoms. Therefore, this group is highly selected and does not permit conclusions about the general incidence of mitral regurgitation in coronary heart disease.

Discrepancies between auscultatory, phonographic, and angiographic findings in this study as well as in others may be explained by the variability of mitral reflux (Heikkilä, 1967, 1971; Shelburne and Gorlin, 1972). This may also hold for the varying character, intensity, and localisation of the systolic murmur. In common with other authors (Burch et al., 1971; Phillips et al., 1963), we have found that the 'diamond shaped' or ejection type murmur, as well as pan- or late systolic murmurs, occurred with mitral regurgitation, but no type of murmur correlated with the grade of reflux on angiography (Heikkilä, 1967, 1971; Shelburne et al., 1968; Sanders et al., 1971; Shelburne and Gorlin, 1972), nor did the intensity and character of the systolic murmur strictly correspond with any particular mechanism of valvar regurgitation (De Busk and Harrison, 1969; Heikkilä, 1971). 'Silent' mitral regurgitation (Aravanis, 1965; Forrester et al., 1971) has been reported, and 15 of our 39 patients with angiographically demonstrable mitral regurgitation had no murmur. However, no statement is possible as to whether mitral regurgitation was 'silent' in those patients when seen on ventriculograms because phonocardiography was not performed during angiocardiography. When mitral regurgitation could be regarded as angiocardiographically significant (grades 2 to $4 / 4$ ) a systolic murmur was usually associated (Table 1). On the other hand, the systolic murmur heard in 29 patients without angiographic evidence of reflux might have been the result of real regurgitation at the time of clinical or phonocardiographic examination. An ejection-type systolic murmur might, of course, have arisen from a minimally sclerosed aortic valve or have been associated with asynergic ventricular contraction interfering with the subvalvar mechanism.

The variability of mitral reflux depends on the mechanism of valvar regurgitation. If it is the result of transient papillary muscle ischaemia (Holmes and Logan, 1968) or reversible localised dyskinesis of the free ventricular wall from acute hypoxia (Herman et al., 1967), the systolic murmur of mitral regurgitation can vary from day to day (De Pasquale and Burch, 1971). A consistent murmur, on the other hand, is highly suggestive of irreversible fibrosis or necrosis of papillary muscle structure (with or without ruptured connection to the mitral valve), or of permanent dyskinesis of the ventricular wall.

Both historically and electrocardiographically, patients with mitral regurgitation had a significantly higher incidence of previous myocardial infarction than those without mitral regurgitation. Unlike some authors (Orlando et al., 1964; Robinson et al., 1965; Morrow et al., 1968; Heikkilä, 1971; Sanders et al., 1971), but in agreement with Heikkilä (1967), we did not find a higher incidence of mitral regurgitation in patients with posteroinferior myocardial infarction than in those with anterior infarction. This distribution corresponded well with the frequency of valvar regurgitation in various patterns of coronary arterial disease. Again, the concept of a complex mechanism of 
mitral closure which may be impaired at different levels of the valvar apparatus is favoured. If papillary muscle dysfunction resulting from ischaemia is the only cause of valvar regurgitation, a higher incidence of reflux from posteromedial papillary muscle dysfunction would be expected since its blood supply is more vulnerable (James, 1968). However, reflux may occur in anterolateral infarction (with or without aneurysm) because of local dyskinesis or abnormal spatial relations even with normal contraction of the anterolateral papillary muscle itself. In this context it is interesting that electrocardiographic criteria of papillary muscle infarction (Phillips et al., 1963; Burch et al., 1971) were rare in our series $(15 \%)$ and were not useful in predicting initral regurgitation. Nor is electrocardiographic evidence of left ventricular hypertrophy a reliable feature of ischaemic mitral regurgitation (Heikkilä, 1971) because it may be masked by myocardial infarction (Shelburne and Gorlin, 1972). Signs of left atrial enlargement on the electrocardiogram (Heikkilä, 1971) are slightly more helpful.

The findings on plain chest radiographs essentially agree with the electrocardiographic findings, i.e. a normally sized left ventricle and atrium do not preclude mitral regurgitation (Heikkilä, 1971), and moderate atrial enlargement is more strongly associated with mitral regurgitation than is left ventricular hypertrophy. Left atrial enlargement appears to be more significantly influenced by raised left ventricular end-diastolic pressure from abnormal function, rather than by volume-overload from mitral reflux, as shown in Table 2 . Left ventricular impairment is significantly related to the incidence of mitral regurgitation but not to its degree (Table 1). Many authors (Sanders et al., 1965; Raftery et al., 1966; Heikkilä, 1971) have attributed the near normal size of the left atrium in ischaemic mitral regurgitation to low compliance of that chamber. Thus, the regurgitant pressure wave is propagated back to the pulmonary venous system with a typically high ' $v$ ' wave (Raftery et al., 1966; Forrester et al., 1971; Heikkilä, 1971) and the radiographic appearance of pulmonary venous hypertension may also explain that a third heart sound and a rapid filling wave are relatively uncommon findings in ischaemic mitral regurgitation. The regurgitant volume returns to the left ventricle later in diastole than in the case of a highly compliant and dilated left atrium in mitral valvar disease, which is usually associated with a third heart sound and a steep rapid filling wave.

The fact that the grade of reflux does not correspond well with the haemodynamic and angiocardiographic grade of left ventricular dysfunction suggests that different mechanisms of valvar regurgitation may lead to various grades of atrial opacification on ventriculography. As shown in Table 3 there was a higher incidence of localised or generalised abnormal left ventricular contraction (Heikkilä, 1971; Shelburne and Gorlin, 1972) in patients with any grade of mitral regurgitation than in those without regurgitation. Conversely, patients with abnormal left ventricular contraction, particularly those with generalised poor contraction from ischaemia, tend to have mitral regurgitation (Table 1). In this latter group left ventricular enlargement itself may interfere with mitral valve closure by abnormal spatial relations between papillary muscles and mitral leaflets (Friedberg, 1966; Hurst and Logue, 1970; Burch et al., 1971).

We thank the physicians and surgeons of the National Heart Hospital for allowing us to study their patients.

\section{References}

Aravanis, C. (1965). Silent mitral insufficiency. American Heart Fournal, 70, 620.

Burch, G. E., De Pasquale, N. P., and Phillips, J. H. (1963). Clinical manifestations of papillary muscle dysfunction. Archives of Internal Medicine, 112, 112.

Burch, G. E., Phillips, J. H., and De Pasquale, N. P. (1971). Papillary muscle dysfunction. In Coronary Heart Disease. A Symposium, pp. 247-261. Ed. by H. I. Russek and B. L. Zohman. Lippincott, Philadelphia.

Cederqvist, L., and Söderström, J. (1964). Papillary muscle rupture in myocardial infarction. Acta Medica Scandinavica, 176, 287.

De Busk, R. F., and Harrison, D. C. (1969). The clinical spectrum of papillary-muscle disease. New England fournal of Medicine, 281, 1458.

De Pasquale, N. P., and Burch, G. E. (1971). Papillary muscle dysfunction in coronary (ischemic) heart disease. Annual Review of Medicine, 22, 327.

Forrester, J. S., Diamond, G., Freedman, S., Allen, H. N., Parmley, W. W., Matloff, J., and Swan, H. J. C. (1971). Silent mitral insufficiency in acute myocardial infarction. Circulation, 44, 877.

Friedberg, C. K. (1966). Diseases of the Heart, 3rd ed. W. B. Saunders, Philadelphia.

Gahl, K., Caspari, P., Pearson, M., Sutton, R., and McDonald, L. (1972). Apical systolic murmurs related to mitral regurgitation at angiography in ischaemic heart disease (abstract). British Heart fournal, 34, 965.

Heikkilä, J. (1967). Mitral incompetence complicating acute myocardial infarction. British Heart fournal, 29, 162.

Heikkilä, J. (1971). The fate of mitral valve complex in acute myocardial infarction. Annals of Clinical Research, 3, 386.

Herman, M. V., Heinle, R. A., Klein, M. D., and Gorlin, R. (1967). Localized disorders in myocardial contraction. New England fournal of Medicine, 277, 222.

Holloway, D. H., Jr., Whalen, R. E., and McIntosh, H. D. (1965). Systolic murmur developing after myocardial ischemia or infarction. Fournal of the American Medical Association, 191, 888.

Holmes, A. M., and Logan, W. F. W. E. (1968). Transient systolic murmurs in angina pectoris. American Heart fournal, 76, 680. 
Hurst, J. W., and Logue, R. B. (1970). (Eds.) The Heart, 2nd ed. McGraw Hill, New York.

James, T. N. (1968). The coronary circulation and conduction system in acute myocardial infarction. Progress in Cardiovascular Diseases, 10, 410.

Morris, J. J., Jr., Estes, E. H., Jr., Whalen, R. E., Thompson, H. K., Jr., and McIntosh, H. D. (1964). P-wave analysis in valvular heart disease. Circulation, 29, 242.

Morrow, A. G., Cohen, L. S., Roberts, W. C., Braunwald, N. S., and Braunwald, E. (1968). Severe mitral regurgitation following acute myocardial infarction and ruptured papillary muscle. Circulation, 37-38, Suppl. 2, 124.

Orlando, M. D., Wooley, C. F., Scarpelli, D., and Ryan, J. M. (1964). Mitral regurgitation caused by infarcted papillary muscles: report of 15 cases (abstract). Circulation, 29-30, Suppl. 3, 136.

Petch, M. C., Sutton, R., and Jefferson, K. E. (1973). Safety of coronary arteriography. British Heart fournal, 35, 377.

Phillips, J. H., Burch, G. E., and De Pasquale, N. P. (1963). The syndrome of papillary muscle dysfunction. Annals of Internal Medicine, 59, 508.

Puff, A., Barrenberg, M., and Goerttle, T. (1965). Röntgenkinematographische Untersuchungen über den Bewegungsmechanismus der Mitralklappe. Fortschritte auf dem Gebiette der Röntgenstrahlen und der Nuklearmedizin, 102, 607.

Raftery, E. B., Oakley, C. M., and Goodwin, J. F. (1966). Acute subvalvar mitral incompetence. Lancet, 2, 360 .

Robinson, J. S., Stannard, M. M., and Long, M. (1965). Ruptured papillary muscle after acute myocardial infarction. American Heart fournal, 70, 233.

Ross, D., Sutton, R., Dow, J., Gonzalez-Lavin, L., Hendrix, G., Jefferson, K., McDonald, L., Petch, M. C., Smithen, C., and Sowton, E. (1972). Venous graft surgery in treat- ment of coronary heart disease. British Medical fournal, $2,644$.

Sanders, C. A., Armstrong, P. W., Willerson, J. T., and Dinsmore, R. E. (1971). Etiology and differential diagnosis of acute mitral regurgitation. Progress in Cardiovascular Diseases, 14, 129.

Sanders, C. A., Scannell, J. G., Harthorne, J. W., and Austen, W. G. (1965). Severe mitral regurgitation secondary to ruptured chordae tendineae. Circulation, 31, 506.

Segal, B. L., and Likoff, W. (1964). Late systolic murmur of mitral regurgitation. American Heart fournal, 67, 757.

Shelburne, J. C., and Gorlin, R. (1972). The diagnosis of papillary muscle dysfunction in coronary artery disease. Geriatrics, 27 (Feb.), 116.

Shelburne, J. C., Rubenstein, D., and Gorlin, R. (1968). The significance of papillary muscle dysfunction in coronary artery disease (abstract). Clinical Research, 16, 249.

Silverman, M. E., and Hurst, J. W. (1968). The mitral complex. Interaction of the anatomy, physiology and pathology of the mitral annulus, mitral valve leaflets, chordae tendineae and papillary muscles. American Heart fournal, 76, 399.

Vandenberg, R. A., Williams, J. C. P., Sturm, R. E., and Wood, E. H. (1969). Effect of ventricular extrasystoles on closure of mitral valve. Circulation, 39, 197.

Yater, W. M., Traum, A. H., Brown, W. G., Fitzgerald, R. P., Geisler, M. A., and Wilcox, B. B. (1948). Coronary artery disease in men 18-39 years of age. American Heart fournal, $36,334,481$, and 683 .

Requests for reprints to Dr. Lawson McDonald, National Heart Hospital, Westmoreland Street, London W1M 8BA. 